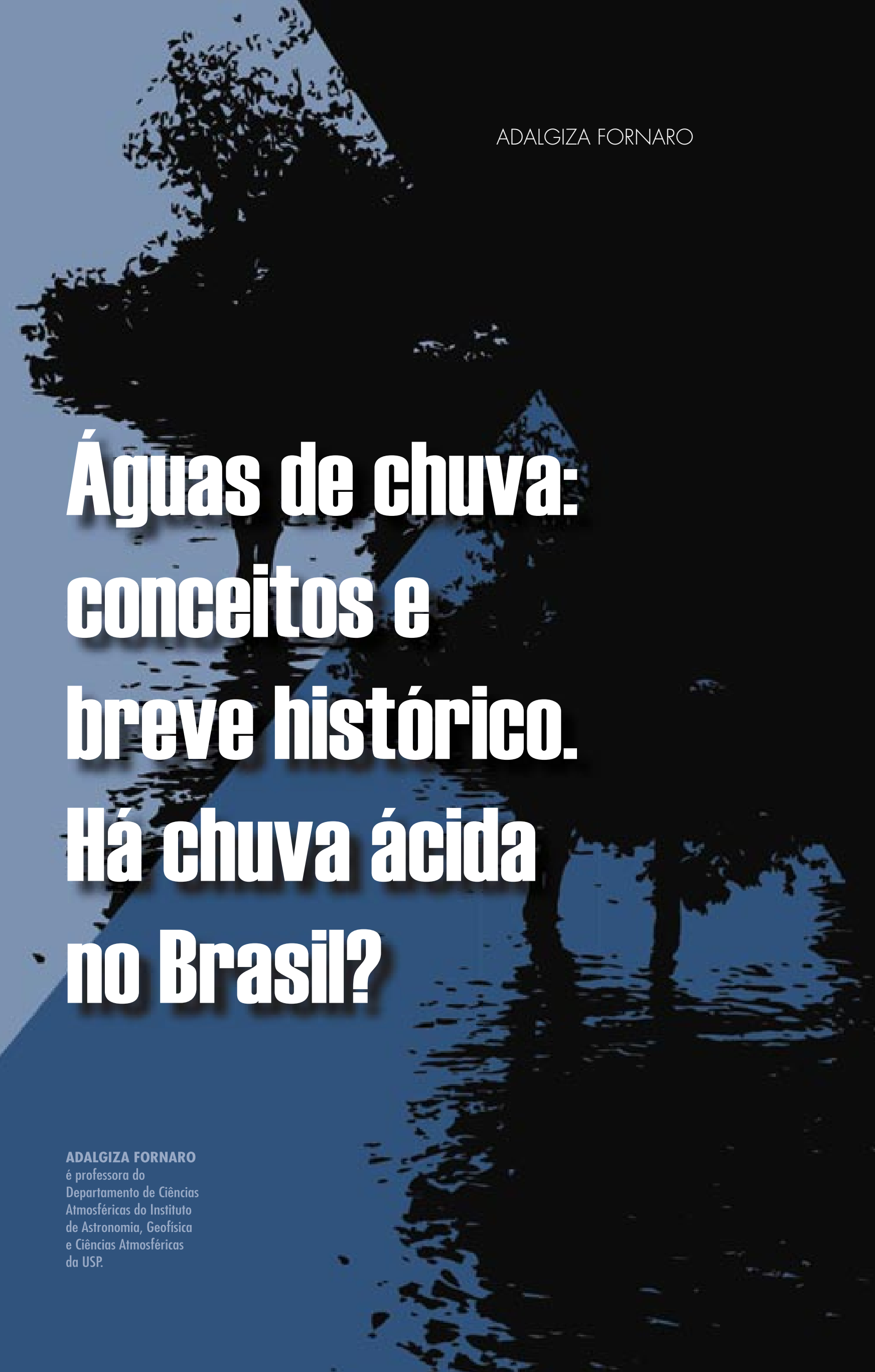




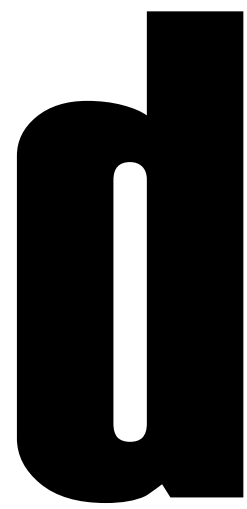

urante a primeira metade do século XX observou-se aumento significativo da acidez das águas de chuva em várias regiões do planeta. Essa acidez foi associada, predominantemente, à presença de ácidos fortes (sulfúrico e nítrico) e ácidos orgânicos (acético e fórmico), originados da oxidação de compostos de enxofre, nitrogênio e carbono, provenientes de processos industriais e da queima de combustíveis fósseis (Cowling, 1982; Fornaro, 1991).

Porém, o termo "chuva ácida" surgiu pela primeira vez no século XIX. Já nessa época constatou-se que a composição química da precipitação era influenciada pela queima de carvão, decomposição de matéria orgânica, direção dos ventos, proximidade do mar, quantidade e frequência de chuva. Observou-se, ainda, que as chuvas ácidas causavam prejuízos às plantas e materiais, além da primeira associação desses efeitos com a presença de ácido sulfúrico (Cowling, 1982).

A caracterização da acidez de águas de chuva baseia-se no equilíbrio entre água pura e dióxido de carbono $\left(\mathrm{CO}_{2}\right)$ atmosférico. Valor de pH 5,6 foi considerado "fronteira natural" nessa caracterização. Porém, valores de pH ao redor de 5 foram observados em regiões não poluídas, variando consideravelmente em função da eficiência da "limpeza atmosférica" pela água de chuva, assim como pelas condições geográficas dos ciclos de enxofre e nitrogênio ou emissões naturais de ácidos orgânicos. Desse modo, considera-se "chuva ácida" aquela que apresentar valor de $\mathrm{pH}<5 \mathrm{e}$ "chuva alcalina" aquela com $\mathrm{pH}>6$. Estudos sobre acidez em águas de chuva em regiões industrializadas mostraram valores de $\mathrm{pH}$ menores que 4,5 chegando a 2 para eventos isolados em algumas regiões. Em eventos com predomínio de espécies alcalinas, ou potencialmente neutralizantes da acidez (por exemplo, amônia, carbonato ou hidróxido), o valor de pH pode ser superior a 7 (Fornaro, 1991). 
Nesse sentido é importante destacar que apenas medidas de valores de $\mathrm{pH}$ podem não ser suficientes para se avaliar o grau de "contaminação" dessas águas de chuva. Portanto, o estudo mais amplo da composição química de águas de chuva pode ser um importante mecanismo de avaliação do nível da poluição do ar, uma vez que é eficiente processo de "limpeza" da atmosfera, levando os poluentes para outros ambientes, como solo, oceanos, lagos, rios, águas subterrâneas, florestas, construção civil, etc.

\section{POLUIÇÃO ATMOSFÉRICA}

Atualmente muitas regiões do planeta estão cercadas por problemas ambientais, sendo um deles a deterioração da qualidade do ar. A Comissão de Saúde e Ambiente da Organização Mundial da Saúde (OMS) tem identificado a poluição do ar como problema de saúde pública já atingindo proporções críticas (WHO, 1994).

O crescimento das populações urbanas e dos níveis de industrialização levou ao aumento da demanda de energia, causando aumento da emissão de poluentes, sendo a combustão de óleos fósseis a principal fonte de poluentes na atmosfera urbana, como: dióxido de enxofre $\left(\mathrm{SO}_{2}\right)$, óxidos de nitrogênio ( $\mathrm{NO}$ e $\mathrm{NO}_{2}$, chamados $\mathrm{NO}_{x}$ ), monóxido de carbono (CO) e material particulado em suspensão.

A poluição do ar provoca efeitos adversos à saúde humana não somente por inalação direta, mas também por rotas indiretas de exposição, como contaminação deáguas potáveis ou alimentos e mesmo absorção pela pele. Os efeitos diretos da poluição do ar sobre a saúde humana variam de acordo com a intensidade e a duração da exposição e também com a própria condição de saúde da população exposta, sendo alguns setores da população mais vulneráveis à poluição do ar como, por exemplo, crianças e idosos. Com efeito, a concentração de alguns poluentes em áreas urbanas poluídas tem sido suficientemente alta para provocar deficiência de funções pulmonares e cardiovasculares, efeitos neurocomportamentais e até aumento de mortalidade (WHO, 1994; Saldiva et al., 1995).

Aqui é interessante lembrar que a maior tragédia ocorrida, devida à alta concentração de poluentes atmosféricos, foi na cidade de Londres em dezembro de 1952. Nessa ocasião somaram-se fatores de intensa emissão de compostos contendo enxofre (queima de carvão) e condições atmosféricas desfavoráveis para a dispersão de poluentes, o que provocou a formação de densa camada de poeira, neblina e gases com alto teor de ácidos. Em torno de 4.000 pessoas morreram após inalar essa "mistura corrosiva".

Somando-se ao impacto negativo na saúde humana, muitos poluentes causam impactos adicionais ou indiretos ao ambiente. Por exemplo, óxidos de enxofre e nitrogênio são precursores da deposição ácida, estando vinculados à acidificação de solos, lagos e rios, afetando adversamente ecossistemas aquáticos e terrestres, muitas vezes centenas de quilômetros distantes da fonte. Além disso, o enfraquecimento e os danos visíveis a materiais (como náilon, borracha e metais), edifícios e obras de arte são atribuídos tanto à deposição seca de gases ( $\mathrm{SO}_{2}, \mathrm{O}_{3}, \mathrm{H}_{2} \mathrm{O}_{2}$, etc.) e material particulado quanto à deposição úmida (águas de chuva, neblina, neve) (WHO, 1994).

A composição química de um evento de chuva é resultado do conjunto de diversos fatores, pois os processos atmosféricos são dinâmicos e complexos, envolvendo emissão, transporte, diluição, transformação química, emissão de poluentes (Figura 1). Assim, a precipitação ácida pode ocorrer como deposição seca ou úmida, não sendo o fenômeno limitado pela presença de chuva. Portanto, atualmente, o conceito mais adequado para o fenômeno da chuva ácida é “deposição ácida”.

As fontes ou emissores de poluentes podem ser tanto naturais (por exemplo, vulcões) quanto devidas à ação humana (por exemplo, processos industriais). Tais fontes também podem ser classificadas como estacionárias (indústrias em geral, postos de gasolina, vulcões, etc.) e mó- 


\section{FIGURA 1 \\ Processos e compostos químicos atmosféricos envolvidos na formação da deposição ácida (Fornaro, 1991)}

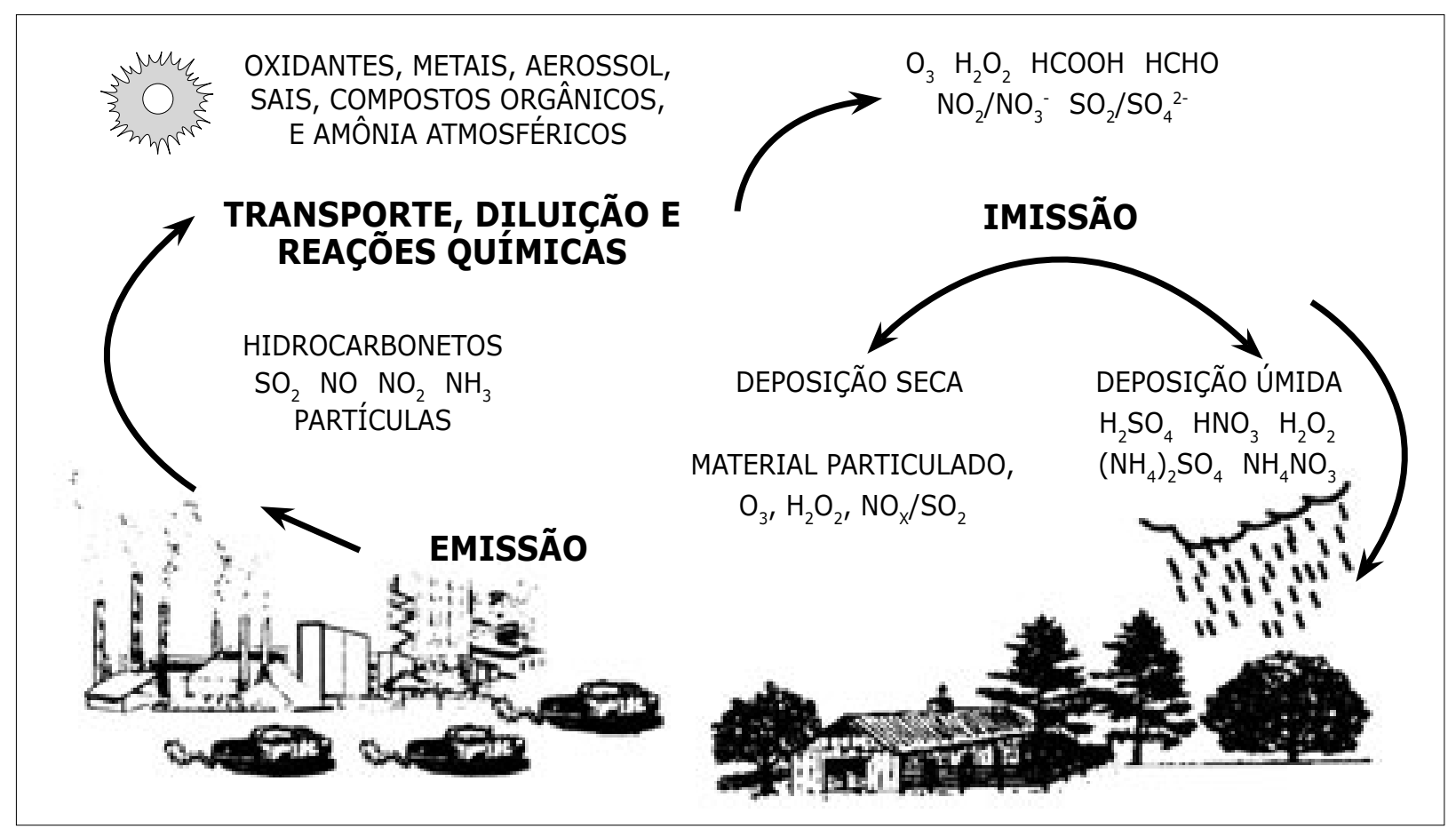

veis (veículos em geral). Dessa forma, na atmosfera podem estar presentes grandes variedades de poluentes, que inicialmente são classificados como:

- poluentes primários - aqueles emitidos diretamente pelas fontes $\left(\mathrm{SO}_{2}, \mathrm{NO}, \mathrm{NH}_{3}\right.$, hidrocarbonetos, material particulado, etc.);

- poluentes secundários - aqueles formados na atmosfera através de reação química entre poluentes primários e constituintes naturais da atmosfera $\left(\mathrm{O}_{3}, \mathrm{H}_{2} \mathrm{O}_{2}\right.$, ácidos sulfúrico e nítrico, etc.).

Dessas principias fontes de poluentes atmosféricos destacam-se a queima de combustíveis (gás natural, carvão, gasolina, álcool, diesel, etc.); processos industriais (fundições, refinarias, fabricação de fertilizantes ou papel, etc.); queimadas (florestas, plantações); sal marinho; erupções vulcânicas; suspensão do material particulado do solo; reações químicas na atmosfera (também classificados como processos de remoção de poluentes, pois quando uma espécie é transformada em outra se tem um mecanismo de remoção da espécie original). Adicionalmente, dentre os principais poluentes originados desses emissores merecem destaque o material particulado (tamanho, massa e composição química variável), os já mencionados $\mathrm{CO}$ e $\mathrm{CO}_{2}, \mathrm{NO}_{\mathrm{x}}, \mathrm{SO}_{2}$, hidrocarbonetos, ácidos orgânicos, além de íons em geral $\left(\mathrm{Cl}^{-}, \mathrm{NO}_{3}{ }^{-}, \mathrm{SO}_{4}{ }^{2-}, \mathrm{Na}^{+}, \mathrm{K}^{+}, \mathrm{NH}_{4}{ }^{+}, \mathrm{Mg}^{2+}\right.$, $\mathrm{Ca}^{2+}$ ), metais ( $\mathrm{Fe}, \mathrm{Cu}, \mathrm{Pb}, \mathrm{Ni}, \mathrm{Cd}$, etc.) e ozônio $\left(\mathrm{O}_{3}\right)$. De forma complementar, a remoção desses poluentes ocorre por dois mecanismos:

1) deposição seca - corresponde à sedimentação gravitacional e à interceptação do material particulado ou absorção de gases por superfícies como solo, vegetação, edificações;

2) deposição úmida - corresponde à absorção de poluentes gasosos (como $\mathrm{SO}_{2}$ ou $\mathrm{NH}_{3}$ ) e partículas por gotas de nuvem (remoção dentro da nuvem) e por arraste durante queda das gotas (remoção abaixo da nuvem) na forma de neblina, chuva ou neve. 


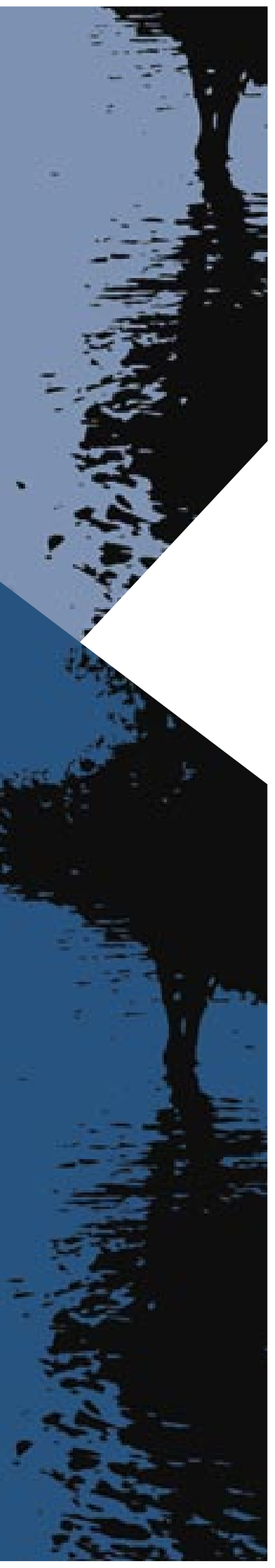

Além disso, é importante lembrar que fatores meteorológicos (ventos, temperatura, umidade relativa, intensidade da radiação solar, percurso e altitude das nuvens, intensidade da chuva, tamanho das gotas, etc.) são também muito importantes nos processos de transformação, dispersão e remoção de poluentes atmosféricos.

\section{BREVE HISTÓRICO DA CHUVA ÁCIDA}

Os primeiros registros de danos na vegetação e saúde humana em virtude de emissões industriais aconteceram na Inglaterra e França em 1661. Nessa época, foram propostos o uso de chaminés altas e a instalação de indústrias distantes dos conglomerados urbanos. Porém, o primeiro monitoramento sistemático da poluição do ar iniciou-se em 1852 pelo químico britânico Robert Angus Smith, que após vinte anos de estudo usou o termo chuva ácida pela primeira vez no livro Air and Rain: the Beginnings of Chemical Climatology, publicado em 1872. Smith constatou que a química da precipitação era influenciada pela combustão do carvão, decomposição da matéria orgânica, direção dos ventos, proximidade do mar, quantidade e freqüiência de chuva. Observou ainda que as chuvas ácidas causavam danos às plantas e materiais, sendo o primeiro pesquisador a associar a eventual presença do ácido sulfúrico às precipitações ácidas (Cowling, 1982).

Apesar desse estudo pioneiro, por quase um século foram desenvolvidos apenas trabalhos isolados como avaliação do efeito da acidez na inibição da germinação e crescimento de plantas; acidificação de solos de florestas; diminuição da produção de trutas causada pela acidez de lagos e rios e outros. Apenas em 1948, na Suécia, instalou-se a primeira rede de monitoramento de águas de chuva na Europa, coordenada por Hans Egner.

Inspirado nos estudos de Smith, em 1950, Eville Gorham, ecologista canadense e doutor em botânica, desenvolveu pesquisas mais detalhadas no conhecimento das causas e efeitos da precipitação ácida nos ecossistemas. Também nessa época, Eriksson, expandindo a rede de monitoramento a partir de Egner, enunciou a teoria da circulação biogeoquímica da matéria através dos diferentes compartimentos terrestres (crosta, oceanos, atmosfera e seres vivos), e, em conjunto com Carl Gustav Rossby, também iniciou os estudos sobre trajetórias de massas de ar.

Após vinte anos de amplo conjunto de análise de dados, envolvendo a composição química de águas superficiais, chuva e solo, Svante Oden (1967) apresentou a primeira teoria completa sobre chuvas ácidas:

- a precipitação ácida é um fenômeno regional de grande escala com fontes e receptores bem definidos;

- águas de chuva, lagos, rios e mares tornaram-se mais ácidas;

- o ar poluído, contendo compostos de enxofre e nitrogênio, é transportado por ventos, cobrindo distâncias de 100 a 2.000 km, através de várias nações na Europa;

- a causa mais provável da deposição ácida na Escandinávia foram ventos com nuvens, contendo compostos de enxofre, vindos da Alemanha e Inglaterra;

- prováveis conseqüências ecológicas:

- mudança da composição química dos lagos;

- diminuição da população dos peixes;

- lixiviação de metais tóxicos a partir dos solos para lagos e rios;

- diminuição do crescimento de florestas;

- aumento de doenças em plantas;

- aceleração de danos a materiais (metal, borracha, tinta, mármore).

Em 1972, na Europa, aconteceu uma importante conferência sobre saúde humana e questões ambientais, na qual, pela primeira vez, o fenômeno da chuva ácida foi apresentado como um problema grave de poluição do ar. Enquanto isso, desde 1963, nos Estados Unidos, acontecia estudo multidisciplinar que mostrava que águas de chuva estavam de 100 a 1.000 vezes mais ácidas no leste americano devido às emis- 
sões pelas indústrias e usinas de geração de energia elétrica de óxidos de enxofre e nitrogênio. Porém, os americanos se convenceram do fenômeno chuva ácida apenas em 1974, após conferências de Svante Oden em várias universidades dos Estados Unidos. Curiosamente, esse momento coincidiu com importante reportagem do The New York Times sobre "o veneno que cai do céu”, que mobilizou o Congresso norteamericanoe provocou a criação do National Atmospheric Deposition Program com coordenação de Ellis Cowling. Esse programa continua em ação, estando todas as etapas e os resultados disponíveis no endereço eletrônico da Environmental Protection Agency (http://www.epa.gov/).

Em 1975, em Columbus (Ohio, EUA), aconteceu o primeiro Simpósio Internacional em Precipitação Ácida e o Ecossistema de Florestas (Acid Rain Conference). Os objetivos dessa reunião eram avaliar o conhecimento acumulado até aquele momento sobre acidez em precipitação e focar a atenção em seus efeitos ecológicos pelo mundo, servindo como fórum de encontro entre diferentes grupos (acadêmico, industrial, governamental e público em geral) para discussão da magnitude, extensão, natureza e conseqüências da precipitação ácida. Desde então, essa conferência ocorre a cada cinco anos em diferentes locais no mundo: Sanderfjord (Noruega, 1980); Muskoka (Canadá, 1985); Glasgow (Escócia, 1990); Göteborg (Suécia, 1995); Tsukuba (Japão, 2000) e Praga (República Tcheca, 2005). A 7aA Acid Rain Conference, em 2005, marcou a transição da visão da deposição ácida como um fenômeno isolado para uma visão de sua inter-relação com outros temas, como mudanças climáticas globais, formação do smog fotoquímico em grandes centros urbanos, mudanças do uso do solo (destruição de florestas), preservação da biodiversidade e da saúde humana.

Apesar de ter sido publicado há quase 25 anos, uma importante referência da abordagem histórica sobre chuva ácida é o artigo "Acid Precipitation in Historical Perspective", publicado por Cowling em 1982. Nesse artigo, o autor mostra a evolução dos problemas causados pela acidez atmosférica, desde as primeiras constatações do aumento da acidez das águas de chuva, rios e lagos, até os danos causados nas populações aquáticas (peixes, algas, crustáceos, etc.), solos, florestas, plantações, materiais (metais, mármores, pinturas, etc.) e mesmo à saúde humana. No referido artigo, também foram descritos programas de monitoramento para avaliação dos processos físicos e químicos que ocorrem na atmosfera, os quais visavam ao desenvolvimento de técnicas para controle de emissões de poluentes (Cowling, 1982). Outra referência importante na descrição do desenvolvimento do conhecimento do fenômeno chuva ácida foi escrito por Kowalock e publicado em 1993. Nesse texto o autor discute as questões multidisciplinares relativas aos grandes temas da poluição atmosférica (Kowalok, 1993).

Após este breve histórico pode-se afirmar que o termo chuva ácida tem sido usado desde os primeiros estudos descrevendo a acidificação da precipitação. Mas, com a expansão das pesquisas sobre esse fenômeno, constatou-se a ocorrência de deposição de espécies ácidas na forma de neve, nuvem, nevoeiro/neblina/garoa e até mesmo em ausência de fase líquida (deposição seca), assim o conceito de chuva ácida foi expandido para deposição ácida. Mas, ainda nos dias atuais, é comum esses dois termos serem usados como sinônimos.

\section{Caracterização química de ÁGUAS DE CHUVA}

Para a caracterização química da precipitação atmosférica têm sido priorizadas as medidas de $\mathrm{pH}$ e condutividade, por serem mais acessíveis; seguindo-se da determinação de $\mathrm{SO}_{4}{ }^{2-}$ e $\mathrm{NO}_{3}^{-}$, sendo que pesquisas mais detalhadas abrangem, em geral, $\mathrm{Cl}^{-}$, $\mathrm{NH}_{4}^{+}, \mathrm{Na}^{+}, \mathrm{K}^{+}, \mathrm{Ca}^{2+} \mathrm{e} \mathrm{Mg}^{2+}$ e, eventualmente, metais pesados e espécies orgânicas como ácidos carboxílicos (Fornaro \& Gutz, 2003; Fornaro, 1991).

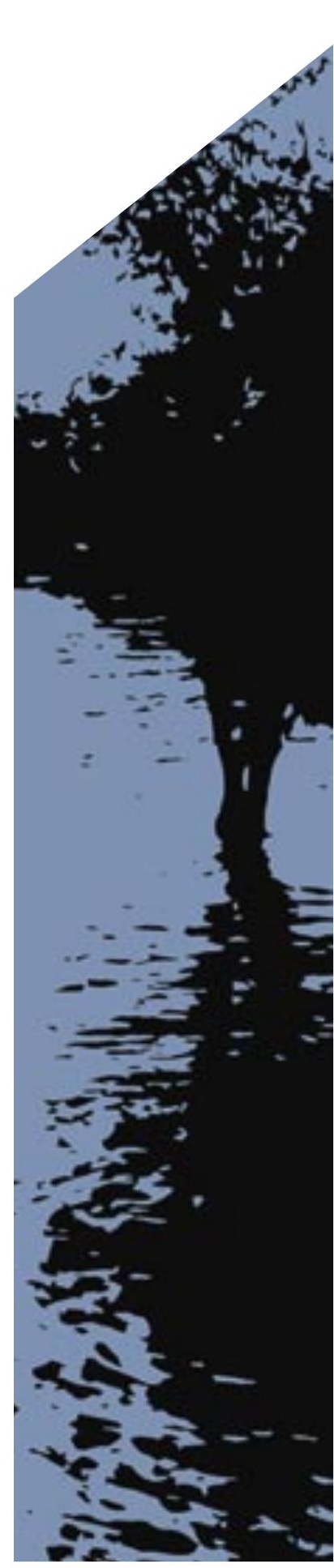


Aimportância do monitoramentodo $\mathrm{pH}$, que provê a atividade (concentração) de íons hidrogênio hidratados, ou seja, acidez ou alcalinidade livre, está no seu impacto sobre a biota, bem como na definição da posição de incontáveis equilíbrios químicos e influência na cinética de reações, incluindo as de corrosão. Porém, deve-se destacar que em águas de chuva de regiões altamente poluídas a medida de $\mathrm{pH}$ pode não ser representativa de carga de poluentes presentes, devido à presença significativa de espécies solúveis que possam neutralizar o excesso de íons hidrogênio, o que torna importante a informação sobre o teor de outros compostos presentes nessas amostras. $\mathrm{Na}$ apresentação das concentrações iônicas em águas de chuva é importante o uso da média ponderada pelo volume (MPV), pois limita a influência de concentrações muito altas que ocorrem em chuvas muito fracas, assim como efeitos de diluição em chuvas muito intensas. O uso da MPV possibilita a comparação entre os resultados da composição química de diferentes estudos (Leal et al., 2004).

\section{COMPOSIÇÃO QUIIMICA DE ÁGUAS DE CHUVA NO BRASIL}

Na Europa, na América do Norte e mesmo em alguns países da Ásia criaram-se programas de monitoramento envolvendo grandes redes de amostragem cobrindo um ou mais países com o objetivo de avaliações tanto espaciais quanto temporais da composição química das águas de chuva e seus efeitos em diferentes ecossistemas (Cowling, 1982).

Por outro lado, no Brasil, efetivamente, não existe rede de monitoramento estabelecida, nem esforços coordenados, e os dados disponíveis originam-se de iniciativas isoladas ou de grupos de pesquisadores limitados a estudos em regiões específicas e por períodos de tempo restritos. Há publicações sobre algumas regiões ou cidades na Amazônia (Andrea et al., 1990; Williams et al., 1997) no estado de São Paulo (MoreiraNordemann et al., 1986; Forti et al., 1990; Fornaro et al., 1993; Paiva et al., 1997; Lara et al., 2001; Rocha et al., 2003; Fornaro \& Gutz, 2003; Leal et al., 2004), no estado Rio de Janeiro (Mello, 2001; Mello \& Almeida, 2004; Souza et al., 2006), Belo Horizonte (Figueredo, 1999), Porto Alegre (Luca et al., 1991), Cuiabá, (Marques et al., 2006). Além desses, foi realizado estudo sobre a influência da presença de termoelétrica a carvão na composição química de águas de chuva no município de Figueira, Paraná (Flues et al., 2002 e 2003) e também na região de Candiota, Rio Grande do Sul (Migliavacca et al., 2004 e 2005).

Alguns resultados de composição química de águas de chuva de diferentes regiões do Brasil e para períodos distintos estão apresentados na Tabela 1. Ilha Grande, Itatiaia e Amazônia Central representam as regiões com menos influência de atividades humanas, apresentando relativamente os menores teores iônicos. Porém, as concentrações mais altas de cloreto e sódio em Ilha Grande e Rio de Janeiro apenas são representativas da influência marítima, ou seja, dissolução nas águas de chuva de partículas de sal marinho presente na atmosfera. Em Belo Horizonte, observou-se a predominância do íon cálcio em virtude da presença de fábricas de cimento na região onde se realizou o estudo. Em todas as regiões estudadas os valores médios de $\mathrm{pH}$ variaram entre 4,5 e 5,5 , portanto, foram águas de chuva entre ácidas e levemente ácidas.

Na tabela destacam-se os resultados de Vila Parisi em Cubatão, que representou uma das maiores tragédias ecológicas do Brasil, conforme matéria publicada no primeiro número da revista Ciência Hoje, em 1982. As águas de chuva da região, entre 1984 e 1985, poderiam ser consideradas como uma "salmoura", devido à significativa presença dos íons dissolvidos, por exemplo, sulfato $\left(\mathrm{SO}_{4}{ }^{2-}\right)$, cuja concentração

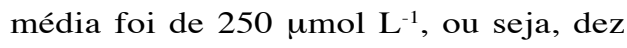
vezes acima das concentrações observadas em São Paulo no mesmo período. Apesar de apresentar valores médios de $\mathrm{pH}$ próximos a 5,5, em Cubatão não se poderia chamar 
TABELA 1

Comparação entre valores médios de pH e concentrações médias ponderadas pelo volume ( $\left.\mu \mathrm{mol} \mathrm{L}^{-1}\right)$ de algumas espécies iônicas presentes em águas de chuva para diferentes regiões do Brasil.

\begin{tabular}{|c|c|c|c|c|c|c|c|c|c|c|}
\hline Local & $\begin{array}{c}\text { Vila Parisi } \\
\text { Cubatão } \\
(\mathrm{SP})\end{array}$ & $\begin{array}{l}\text { São Paulo } \\
\text { (SP) }\end{array}$ & $\begin{array}{c}\text { Amazônia } \\
\text { Central } \\
\text { (AM) }\end{array}$ & $\begin{array}{l}\text { Rio de Ja- } \\
\text { neiro (RJ) }\end{array}$ & $\begin{array}{c}\text { Belo Hori- } \\
\text { zonte (MG) }\end{array}$ & $\begin{array}{l}\text { Piracicaba } \\
\text { (SP) }\end{array}$ & $\begin{array}{c}\text { São Paulo } \\
\text { (SP) }\end{array}$ & $\begin{array}{l}\text { Figueira } \\
\text { (PR) }\end{array}$ & $\begin{array}{c}\text { Candiota } \\
\text { (RS) }\end{array}$ & $\begin{array}{c}\text { Ilha Grande } \\
\text { (RJ) }\end{array}$ \\
\hline Data & $\begin{array}{l}4 / 1984- \\
10 / 1985\end{array}$ & $\begin{array}{l}10 / 1983- \\
10 / 1985\end{array}$ & $\begin{array}{c}10 / 1988- \\
6 / 1990\end{array}$ & $\begin{array}{l}\text { 9/1988- } \\
8 / 1989\end{array}$ & $\begin{array}{c}10 / 1993- \\
2 / 1994\end{array}$ & $\begin{array}{l}8 / 1997- \\
7 / 1998\end{array}$ & $\begin{array}{l}7 / 2002- \\
2 / 2003\end{array}$ & $\begin{array}{l}6 / 1999- \\
6 / 2000\end{array}$ & $1-6 / 2001$ & $3-9 / 2002$ \\
\hline $\mathrm{pH}$ & $>5,5$ & 5,0 & 4,7 & 4,77 & 5,15 & 4,5 & 4,99 & 5,0 & 5,33 & 5,05 \\
\hline $\mathrm{Cl}^{-}$ & 172 & 16,6 & 4,6 & 66,6 & - & 6,0 & 8,54 & 16 & 7,57 & 178,2 \\
\hline $\mathrm{NO}_{3}^{-}$ & 70,6 & 30,0 & 4,2 & 15,8 & 12,0 & 13,8 & 21,2 & 13 & 5,22 & 12,0 \\
\hline $\mathrm{SO}_{4}^{2-}$ & 250 & 24,0 & 1,0 & 20,6 & 12,6 & 7,4 & 12,4 & 35 & 7,3 & 17,4 \\
\hline $\mathrm{Na}^{+}$ & 84,8 & 10,0 & 2,4 & 62,6 & - & 2,1 & 15,0 & 35 & 5,27 & 142,2 \\
\hline $\mathrm{Ca}^{2+}$ & 346 & 20,0 & 1,2 & 15,1 & 22,0 & 2,1 & 5,33 & 16 & 4,42 & 4,6 \\
\hline $\mathrm{NH}_{4}^{+}$ & 93,5 & 37,8 & 3,0 & 18,8 & 18,1 & 11,6 & 37,6 & 30 & 5,81 & 9,9 \\
\hline Ref. & $\begin{array}{c}\text { Moreira- } \\
\text { Nordemann } \\
\text { et al., } 1986\end{array}$ & $\begin{array}{c}\text { Forti et al., } \\
1990\end{array}$ & $\begin{array}{l}\text { Williams et } \\
\text { al.,1997 }\end{array}$ & Mello, 2001 & $\begin{array}{c}\text { Figueredo, } \\
1999\end{array}$ & $\begin{array}{c}\text { Lara et al., } \\
2001\end{array}$ & $\begin{array}{c}\text { Leal et al., } \\
2004\end{array}$ & $\begin{array}{c}\text { Flues et al., } \\
2002\end{array}$ & $\begin{array}{l}\text { Migliavacca } \\
\text { et al., } 2005\end{array}$ & $\begin{array}{l}\text { Souza et } \\
\text { al., } 2006\end{array}$ \\
\hline
\end{tabular}

propriamente de chuva ácida, pois foram registrados resultados com valores de $\mathrm{pH}$ superiores a 9, portanto, chuvas alcalinas (Moreira-Nordemann et al., 1986). Tanto em Cubatão como em outras áreas do Brasil, as indústrias foram as principais responsáveis pelas altas concentrações de poluentes atmosféricos durante o período dos anos 70. Assim, a partir de 1980, ações governamentais foram desenvolvidas para controle da emissão de poluentes (http://www.cetesb.sp.gov.br). Infelizmente, não existem dados mais recentes de composição química de águas de chuva para Cubatão.

Os estudos recentes que indicam a presença de quantidades relativamente mais altas de íons nitrato e amônio em águas de chuva nos centros urbanos são indicativos da influência das emissões veiculares nesses ambientes. O aumento da frota veicular é o principal causador de problemas de poluição atmosférica em grandes centros urbanos como São Paulo e Rio de Janeiro, pois tanto veículos a gasolina (contendo $22 \%$ de álcool anidro) quanto a álcool são emissores de $\mathrm{NO}_{x}$ e aldeídos, importantes precursores dos constituintes das chuvas ácidas e do smog fotoquímico. Devido aos problemas da poluição gerada por veículos, a Cetesb e o Conselho Nacional do Meio Ambiente (Conama) vêm adotando o Programa de Poluição do Ar por Veículos Automotores (Proconve), que foi implementado a partir 
de 1988 com o objetivo de estabelecer limites de emissão de $\mathrm{CO}, \mathrm{NO}_{\mathrm{x}}, \mathrm{SO}_{2}$, material particulado e outros poluentes (http://www. cetesb.sp.gov.br).

\section{CONSIDERAÇ̃ES FINAIS}

Considerando a extensa área territorial do Brasil com grande diversidade de atividades industriais, exploração mineral, atividades agrícolas diversas, somadas aos graves problemas causados pelas queimadas, os estudos existentes sobre composição química de águas de chuva são praticamente pontuais. Porém, pode-se concluir que há chuva ácida no Brasil, apesar de pouco se saber da extensão exata do problema. Atualmente, nos grandes centros urbanos, além das emissões industriais, a emissão veicular tem contribuído significativamente para a degradação da qualidade do ar. Assim, pensando-se nesses centros urbanos como grande fonte de poluentes atmosféricos, que podem ser transportados para regiões distantes, seguido de remoção por precipitação atmosférica, não existem dados envolvendo os possíveis efeitos sobre ecossistemas naturais. Nesse sentido os compostos contendo nitrogênio $\left(\mathrm{NO}_{3}{ }^{-} \mathrm{e}\right.$ $\mathrm{NH}_{4}^{+}$) são exemplos importantes de nutrientes que podem causar processos de eutrofização em corpos d'água, chegando a comprometer sistemas de fornecimento de água para abastecimento público.

\section{BIBLIOGRAFIA}

ANDREAE, M. 0.; TAlBOT, R. W.; BeRRESHEIM, H. \& BEECHER, K. M. "Precipitation Chemistry in Central Amazonia", in Journal Geophysical Research 95(D10), 16987-16999, 1990.

COWLING, E. "Acid Precipitation in Historical Perspective", in Environmental Science Technology 16(2), 110A-123A, 1982. FIGUEREDO, D. V. "Influence of Calcareous Soil Particulates on Acid Rain: Belo Horizonte Metropolitan Region, Brazil", in Ambio 28(6), 1999, pp. 514-8.

FLUES, M.; HAMA, P.; LEMES, M. J. L.; DANTAS, E. S. K. \& FORNARO, A. "Evaluation of the Rainwater Acidity of a Rural Region Due to a Coal Fired Power Plant in Brazil", in Atmospheric Environment 36, 2002, pp. 2397-2404. FLUES, M.; HAMA, P. \& FORNARO, A. “Avaliação do Nível da Vulnerabilidade do Solo Devido à Presença de Termelétrica a Carvão (Figueira, PR - Brasil)", in Química Nova 26(4), 2003, pp. 479-83.

FORNARO, A. "Chuva Ácida em São Paulo: Caracterização Química de Amostras Integradas e Seqüenciais de Deposição Úmida". Dissertação de mestrado. São Paulo, Universidade de São Paulo, Instituto de Química, 1991.

FORNARO, A. \& GUTZ, I. G. R. "Wet Deposition and Related Atmospheric Chemistry in the São Paulo Metropolis, Brazil: Part 2, Contribution of Formic and Acetic Acids", in Atmospheric Environment 37, 2003, pp. 117- 28.

FORTI, M. C.; MOREIRA-NORDEMANN, L. M.; Andrade, M. F.; ORSINI, C. Q. "Elements in the Precipitation of S. Paulo city (Brazil)", in Atmospheric Environment 24B, 1990, pp. 355-60.

KOWALOK, M. E. "Common Threads: Research Lessons from Acid Rain, Ozone Depletion and Global Warming”, in Environment 35(6), 1993, pp. 12-21.

LARA, L. B. L. S.; ATAXO, P.; MARTINELLI, L. A.; VICTORIA, R. L.; CAMARGO, P. B.; KRUSCHE, A.; AYERS, G. P.; FERRAZ, E. S. B. \& BALLESTER, M. V. "Chemical Composition of Rainwater and Anthropogenic Influences in the Piracicaba River Basin, Southeast Brazil", in Atmospheric Environment 35, 2001, pp. 4937-4945.

LEAL, T. F. M.; FONTENELE, A. P. G.; PEDROTTI, J. J. \& FORNARO, A. “Composição lônica Majoritária de Águas de Chuva na Região Central de São Paulo", in Química Nova 27 (6), 2004, pp. 855-61.

LUCA, S. J.; CASTRO, C. B. \& IDE, C. N. "Contaminação da Chuva e da Drenagem Pluvial”, in Ambiente, 4(1), 1990, pp. $49-53$. 
MARQUES, R.; ZAMPARONI, C. A. G. P.; SILVA, E. C.; BARBOSA, A. M.; ARRUDA, D.; EVANGELISTA, S. \& MAGALHÃES,

A. "Ensaios Preliminares para o Monitoramento da Acidez da Chuva em Cuiabá", in Caminhos de Geografia

- revista on line 21 (17), 2006, pp. 225-36, (http://www.ig.ufu.br/revista/caminhos.html).

MELLO, W. Z. de. "Precipitation Chemistry in the Coast of the Metropolitan Region of Rio de Janeiro, Brazil", in Environmental Pollution 114, 2001, pp. 235-42.

MELLO, W. Z. \& ALMEIDA, M. D. de. "Rainwater Chemistry at the Summit and Southern Flank of the Itatiaia Massif, Southeastern Brazil", in Environmental Pollution, 129, 2004, pp. 63-8.

MIGLIAVACCA, D.; TEIXEIRA, E. C.; PIRES, M. \& FACHEL, J. "Study of Chemical Elements in Atmospheric Precipitation in South Brazil", in Atmospheric Environment 38, 2004, pp. 1.641-56.

MIGLIAVACCA, D. M.; TEIXEIRA, E. C.; MACHADO, A. C. M. \& PIRES, M. R. "Composiç̃̃o Química da Precipitação

Atmosférica no Sul do Brasil - Estudo Preliminar", in Química Nova 28(3), 2005, pp. $371-9$.

MOREIRA-NORDEMANN, L. M.; DANELON, O. M.; FORTI, M. C.; SANTO, C. M. E.; SARDELA, D. D.; LOPES, J. C.; FILHO,

B. M. \& ABBAS, M. M. "Caracterização Química das Águas de Chuva de Cubatão", in Relatório Final, INPE-3695RPE/515, 1986, 2005.

PAIVA, R. P.; PIRES, M. A. F.; MUNITA, C. S.; ANDRADE, M. F.; GONÇALVES, F. L. T. \& MASSAMBANI, 0. “A Preliminary Study of the Anthropogenic Contribution to São Paulo Rainfall", in Fresenius Environmental Bulletin 6, 1997, pp. 508-13.

ROCHA, F. R.; FRACASSI DA SILVA, J. A.; LAGO, C. L.; FORNARO, A. \& GUTZ, I. G. R. "Wet Deposition and Related Atmospheric Chemistry in the São Paulo Metropolis, Brazil: Part I. Major Inorganic lons in Rainwater as Evaluated by Capillary Electrophoresis with Contactless Conductivity Detection", in Atmospheric Environment37, 2003, pp. 105-15.

SALDIVA, P. H. N.; POPE, C. A.; SCHWARTZ, J.; DOCKERY, D. W.; LICHTENFELS, A. J.; SALGE, J. M.; BARONE, I. \&

BOHM, G. M. "Air-pollution and Mortality in Elderly People - a Time-series Study in São Paulo, Brazil", in Archives of Environ. Health, 50(2), 1995, pp. 159-63.

SCHWARTZ, S. E. "Acid Deposition: Unraveling a Regional Phenomenon", in Science 243, 1989, pp. 753-63.

SOUZA, P. A.; MELLO, W. Z. de; MALDONADO, J. \& EVANGELISTA, H. “Composição Química da Chuva e Aporte Atmosférico na llha Grande, RJ", in Química Nova, 29(3) , 2006, pp. 471-6.

WHO - World Health Organization. "Air Pollution in the World's Megacities - A Report from the United Nations Environment Programme and the World Health Organization", in Environment, 36(2), 1994, pp. 4-37.

WILLIAMS, M. R.; FISHER, T. R. \& MELACK, J. M. "Chemical Composition and Deposition of Rain in the Central Amazon, Brazil", in Atmospheric Environment 31, 1997, pp. 207-17. 